\title{
Labyrinthe
}

32 | 2009 (1)

Le petit théâtre intellectuel

\section{Le Porte-Parole}

David Schreiber

\section{OpenEdition}

\section{Journals}

Édition électronique

URL : http://journals.openedition.org/labyrinthe/3987

DOI : $10.4000 /$ labyrinthe.3987

ISSN : 1950-6031

Éditeur

Hermann

Édition imprimée

Date de publication : 19 juin 2009

Pagination : 49-52

ISBN : 978-2-7056-6885-3

\section{Référence électronique}

David Schreiber, «Le Porte-Parole », Labyrinthe [En ligne], 32 | 2009 (1), mis en ligne le 01 février 2011, consulté le 02 mai 2019. URL : http://journals.openedition.org/labyrinthe/3987 ; DOI : 10.4000/ labyrinthe.3987 


\section{Le petit théâtre intellectuel}

\section{LE PORTE-PAROLE}

Le Porte-parole est angoissé. Il ne sait plus pourquoi il existe. L'Histoire l'aurait-elle trahi? Elle lui avait tant promis; elle avait juré qu'il parlerait pour elle. Mais le doute a surgi. Aujourd'hui tous dansent autour de son corps meurtri, préparant son cortège funèbre.

Il se souvient du bon vieux temps, du très vieux temps. Même avant l'ère démocratique, il avait su se faire entendre, à petite voix, certes, mais ce n'était pas rien. Tribuns de la plèbe au temps des patriciens, bourgeois des villes en terres féodales, Tiers encastré dans l'État, ambassadeurs, missionnaires, voyageurs aux pays des « autres ». Puis arriva l'heure des grandes scènes: celle de "l'homme » au milieu des citoyens, celle enfin de l'être nu, l'être du rien, au milieu des propriétaires, des qualifiés, des compétents, des méritants, des « hommes » même, j'en passe et des meilleurs.

Autour de lui et lui seul, la vie politique s'était organisée: parlement, parti, mandat, délégué, opinion publique, pétition, lobbying. Tout un savoir-faire lentement élaboré, depuis le tract, la motion, le vote, le vote sur les modalités du vote, et le vote préalable au vote sur les modalités du vote. La puissance du langage avait fini par faire l'objet d'une attention spéciale, slogans et mots d'ordres répétés à l'infini, agit-prop, ronéo, poly, photocops. Il se souvient de la chaude atmosphère des congrès, des coordinations, des collectifs. Des images fugaces lui traversent l'esprit, dont il ne sait plus s'il ne les a pas rêvées : on avait, semble-t-il, le droit de fumer en public, de se coucher tard, de confondre le jour et la nuit, le travail et le rêve. Il se souvient des illustres ancêtres, vieux barbus capables de faire entrer les foules en transe, de les faire hurler de joie " comme tordues brusquement dans un accès d'épilepsie ». Même le hasard pouvait parfois s'en mêler - l'Histoire fait bien les choses -, hasard de se retrouver tout à coup à la tête du cortège, pour avoir dit les mots qui rallient, sans même y penser. C'est arrivé, oui, c'est arrivé! Les écrivains, à la grande époque, avaient d'ailleurs su tirer parti de tout ce savoir accumulé. Porte-parole en robe de chambre, n'avaient-ils pas pour tâche d'exprimer leur temps et son époque? De peindre la souffrance? 
Ceux qui manquaient de voix pouvaient au moins écrire. Il y avait même de la noblesse dans ce geste, " prêter sa plume".

Aujourd'hui tout se dérobe. Il a beau continuer, il n'y croit plus.

Certes, des pétitions circulent, nombreuses, rapides, avec des listes longues, de plus en plus longues, d'interminables «premiers signataires ", faisant la part belle à l'Expert, au Comique, au « relais d'opinion »: le «peuple» a disparu derrière le people. Ces pétitions sortent-elles d'ailleurs de la Large Toile, aussi Mondiale soit-elle? Peu probable. Des « appels » sont lancés, comme autant de bouteilles à la mer. On les date pour mieux s'y retrouver, ce qui ne les empêche guère de flotter sans destination sur le calendrier. Il y a bien des positions de repli, pour tâcher de sauver l'essentiel: certains « surveillent», « alertent», « veillent». Des Spécialistes et des Experts compatissants, Renégats pour la plupart, viennent au secours des malheureux: la " société » est ainsi faite, nous vivons une démocratie de la « défiance ». D'autres cherchent à séduire: « cessez de pleurnicher, regardez-vous en face, cherchez au moins le (Contre-)Expert qui est en vous, hissez votre savoir à la hauteur du nôtre, qu'on puisse enfin débattre. » D'autres encore ne font pas de cadeau: « votre vérité éclate, Porte-parole, et vous avec! Vous étiez un tricheur, un manipulateur, vous imposiez les noms, vous forciez les intérêts, vos archives des paroles oubliées sont des montages techniques, ces paroles sont les vôtres, avouez! D'ailleurs votre basisme était un poujadisme! » Naguère un grand Spécialiste - au destin étrange - avait fait une belle leçon: « donner à chacun les moyens de fonder sa propre rhétorique, cela devrait être l'ambition de tous les porte-parole, qui seraient sans doute bien autre chose que ce qu'ils sont s'ils se donnaient le projet de travailler à leur propre dépérissement ». Rusé, il ajoutait : " on peut bien rêver pour une fois ». Ses frères en prophétisme, Témoins dans le style de Cassandre, Experts dans le style de Benoîte, annoncent avec fracas qu'il faut quitter les lieux ou les subvertir définitivement: « il n'y a pas à critiquer les assemblées ou à les déserter, mais à y libérer la parole, les gestes et les jeux entre les êtres. Il suffit de voir que chacun n'y vient pas seulement avec un point de vue, une motion, mais avec des désirs, des attachements, des capacités, des forces, des tristesses et une certaine disponibilité. Si l'on parvient ainsi à déchirer ce fantasme de l'Assemblée Générale au profit d'une telle assemblée des présences [...] il y a quelques chances que se produise une de ces prises en masse, l'un de 


\section{Le Porte-Parole}

ces phénomènes de cristallisation collective où une décision prend les êtres, dans leur totalité ou seulement pour partie».

Ces pensées fortes touchent le Porte-parole et le font réfléchir. Mais l'idéologie ambiante, celle qui veut sa mort, va rarement jusque-là. Elle s'attaque plutôt - faisons l'Expert - à ses « fondamentaux »: le Nombre, le Tort, l'Universel. Lui a fini par croire que le monde était conforme au tableau qu'on lui tend: ère des « individus », universel facile des minorités, des identités multiples et des hommes pluriels. Le compte n'est plus possible. Allez donc dénombrer dans un Tout illimité! Qui fait « majorité »? Où sont donc ceux d'en face? À qui faut-il s'adresser? Il faut bien pouvoir généraliser l'expérience collective! Mais contrairement à l'Expert, la Science importe peu au Porte-parole: ses causes ne sont pas les lois du monde social. Cause du peuple, cause de l'autre, cause du Bien, du Juste, des victimes en tout genre, «cause toujours! » lui répond le chœur en écho. Au nom de qui scander "nous sommes tous" quand chacun parle en son nom propre? Face à la souffrance extrême, le Témoin fait valoir ses droits. L'appareil idéologique d'État et son extension médiatique ne s'y sont pas trompés : armés des sondages, des noms collectifs, de la puissance du général, dont ils semblent avoir acquis définitivement le monopole - le grand Wiki lui-même est devenu complice-, ils savent aussi montrer quand il le faut la souffrance nue, la parole seule, singulière, authentique. Le rapport ministériel et le micro-trottoir sont les faces d'une même pièce. Qu'un Porte-parole surgisse, on saura le caser. S'il a du talent, on l'invitera à s'exprimer sur un plateau d'argent; on lui tendra le piège: « mais pour qui parlez-vous? », «l'avez-vous vécu?». Ultime ironie de l'Histoire traîtresse, car à la grande époque on disait la même chose: « d'où parles-tu camarade? »

Ainsi relégué dans les coulisses, le Porte-parole attend et espère en secret. Qui sait? L'Histoire n'est pas à une traîtrise près. Son heure pourrait revenir... Il y a des Rêveurs qui le disent, quelques Revuistes aussi. Le grand Spécialiste de naguère ne s'y était-il pas laissé prendre lui-même?

D. S. 


\section{Bibliographie, références, lectures}

I. Jacques Rancière, La nuit des prolétaires, Archives du rêve ouvrier, Paris, Fayard, 1981.

II. Victor Flax, Les hommes du jour, $\mathrm{n}^{\circ} 3$ (1908), à propos de Jaurès.

III. Pierre Bourdieu, Questions de sociologie, Paris, Minuit, 2002, p. 18.

IV. Comité invisible, L'insurrection qui vient, Paris, La Fabrique, 2007, p. 133.

V. Jean-Claude Milner, « Une conversation sur l'universel », Cahiers d'études lévinassiennes, $\mathrm{n}^{\circ}$ 6, 2007, pp. 77-91.

VI. « Porte-parole» sur Wikipédia: «Un porte-parole est une personne dont le rôle est de prendre la parole au nom des autres.

Dans le monde particulièrement sensible aux médias, de nombreuses organisations, qu'elles soient privées (entreprises) ou publiques (gouvernements), ou des individus (célébrités), emploient généralement des professionnels qui ont reçu une formation en journalisme, communication et en relations publiques. Leur rôle est de veiller à ce que les annonces soient faites de la manière la plus appropriée et en recherchant à maximiser l'impact favorable des messages (et donc de minimiser l'impact défavorable). » http://fr.wikipedia.org/wiki/Porte-parole (consulté le 14 février 2009). 